\title{
Erratum to: Nonlabens marina sp. nov., a novel member of the Flavobacteriaceae isolated from the Pacific Ocean
}

\author{
Sanghwa Park - Susumu Yoshizawa - Hiroshi Xavier Chiura • \\ Yuki Muramatsu - Yasuyoshi Nakagawa • \\ Kazuhiro Kogure $\cdot$ Akira Yokota
}

Published online: 31 July 2012

(C) Springer Science+Business Media B.V. 2012

\section{Erratum to: Antonie van Leeuwenhoek DOI 10.1007/s10482-012-9765-4}

Both in the title and text occurrences of the original publication, the species epithet Nonlabens marina sp. nov., has been misspelled. The correct spelling should be Nonlabens marinus sp. nov.

The authors thank Professor Jean Euzéby for advice concerning the correct nomenclature of this species.

The online version of the original article can be found under doi:10.1007/s10482-012-9765-4.

S. Park $(\bowtie) \cdot$ A. Yokota

Institute of Molecular and Cellular Biosciences,

The University of Tokyo, 1-1-1 Yayoi, Bunkyo-Ku,

Tokyo 113-0032, Japan

e-mail: psh214@hotmail.com

S. Yoshizawa · H. X. Chiura · K. Kogure

Atmosphere and Ocean Research Institute, The University of Tokyo, 5-1-5 Kashiwanoha, Kashiwa, Chiba 277-8564, Japan

Y. Muramatsu · Y. Nakagawa

Department of Biotechnology, Biological Resource

Center (NBRC) National Institute of Technology

and Evaluation, Kisarazu, Chiba 292-0818, Japan 